\title{
El silencio y lo indecible como morada del ser: Wittgenstein, Heidegger y Rosenzweig. Filósofos entre ruinas.
}

\author{
Silence and the unspeakable as a dwelling place of being: Wittgenstein, Heidegger \\ and Rosenzweig. Philosophers among ruins.
}

DOI: 10.32870/sincronia.axxv.n79.4a21

\author{
Carlos Alberto Navarro Fuentes \\ Tecnológico de Monterrey. (MÉXICO) \\ CE: betoballack@yahoo.com.mx / ID ORCID: 0000-0003-4647-9961
}

Esta obra está bajo una Licencia Creative Commons Atribución-NoComercial 4.0 Internacional

Recibido: $25 / 07 / 2020$

Revisado: 03/10/2020

Aprobado: 05/11/2020

\section{RESUMEN}

El objetivo del ensayo consiste en seguir las huellas del silencio filosóficamente, como multiplicidad no reductible a la unidad; hay instancias de silencio, no el silencio, ni objetiva ni subjetivamente considerado; no es un 'objeto' ni una 'vivencia subjetiva'. Reconocer la relevancia del silencio a partir de su aparente irrelevancia, y, no obstante, hacer notar la importancia que puede tener en el intento por reconducir a la reflexión filosófica y al filosofar en general a lo esencial que hay en ella: PENSAR. El camino que se propone requiere ESCUCHAR al lenguaje, más que dar por sentada la inmediata disposición y transparencia con la cual -en apariencia- el mundo se nos presenta. Para ello, reflexionaremos a partir de extractos de obras escritas por tres pensadores que vivieron 'la guerra' de cerca: Ludwig Wittgenstein (1889-1951), Martin Heidegger (1889-1976) y Franz Rosenzweig (1886-1929). Este trabajo procede peripatéticamente, en solitario, afloran reflexiones en medio de un mundo que se desmorona entre la complejidad y la destrucción que han traído la técnica y la Modernidad. Se emprende acogiendo resonancias, sensaciones, representaciones, imágenes, versos y cavilaciones, reflexionando en medio del aturdimiento cotidiano. ¿Hay un silencio lógico-gramatical o un silencio ético-místicolitúrgico? ¿Equivale el silencio a una imposibilidad de decir o es resultado de una imposibilidad del decir mismo, que no dice cuando lo que más quiere es decir? 
¿Enmudecimiento de la existencia o silencio frente a los acontecimientos que amenazan con rebasarnos? ¿Calla el silencio o enmudece el ser?

Palabras Clave: Silencio. Lenguaje. Camino. Mundo. Pensar. Conocimiento.

\section{ABSTRACT}

The objective of the essay is to follow the tracks of silence philosophically, as multiplicity not reducible to unity; there are instances of silence, not silence, neither objectively nor subjectively considered; it is not an 'object' or a 'subjective experience'. Recognize the relevance of silence based on its apparent irrelevance, and, nevertheless, point out the importance that it can have in the attempt to lead to philosophical reflection and to philosophize in general what is essential in it: THINKING. The proposed path requires LISTENING to language, rather than taking for granted the immediate disposition and transparency with which the world appears to us. To do this, we will reflect on excerpts from works written by three thinkers who lived 'war' up close: Ludwig Wittgenstein (1889-1951), Martin Heidegger (1889-1976) and Franz Rosenzweig (1886-1929). This work proceeds peripathetically, alone, reflections emerge in the middle of a world that crumbles between the complexity and destruction that technique and modernity have brought. It is undertaken by welcoming resonances, sensations, representations, images, verses and musings, reflecting in the midst of daily daze. Is there a logical-grammatical silence or an ethicalmystical-liturgical silence? Is silence equivalent to an impossibility of saying or is it the result of an impossibility of saying itself, which does not say when what it most wants to say? Silence of existence or silence in the face of events that threaten to overwhelm us? Is silence silent or is being silent?

Keywords: Silence. Language. Path. World. Think. Knowledge.

Japonés: La andanza de semejante diálogo deberá tener carácter propio, de modo que habría en él más silencio que conversación. Inquiridor: Ante todo, silencio sobre el silencio... Japonés: ...porque hablar y escribir sobre el silencio ocasiona discusiones perniciosas... Inquiridor: ¿Quién podría mantener simplemente silencio sobre el silencio? Japonés: Esto sería el verdadero Decir... Inquiridor: ...y quedaría el preludio permanente al verdadero diálogo del habla. Japonés: ¿No intentamos así lo imposible?

"De un diálogo acerca del habla entre un japonés y un inquiridor" Martin Heidegger 


\section{La incitación del silencio}

\section{¿Por qué escribe un hombre? Porque no posee carácter suficiente para no escribir}

Karl Kraus

“La pasión de Juana de Arco" (1922), ${ }^{1}$ dirigida por Carlo Dreyer, en lugar de usar tomas fijas al rostro de la acusada, dirige la cámara recurrentemente a las manos, forma de comunicación no verbal. Cuando Juana lleva sus manos al rostro intentando o señalando la intención de acallar el inminente grito de quien sabe el fallo de su juicio de antemano: la muerte, con toda la presencia simbólica y litúrgica de Dios en el ritual requerido por los juicios de la época en plena Guerra de los Cien Años entre Francia e Inglaterra, (1337-1453), opta por morderse un dedo, romper el culposo silencio de la angustia irredimible, no hay salvación posible. Los inquisidores observan como si fuesen espías, con miradas clandestinas y de insana curiosidad al interior de la celda donde la devota y patriota Juana aguarda su destino. El silencio que transmite la escena parece confabular, conspirar también en contra de la acusada. El mirar del espectador del film, del que mira ante el abrumador silencio y la espera parecen convertirlo a su vez en parte del jurado, un jurado que cumple meras funcionas estéticas durante el proceso que se le sigue en la pantalla -y que también sabe que la suerte está echada-, la cual parece no servir para establecer límites entre adentro y afuera, entre los que se mueven al interior del film y los que se encuentran fuera de ella, todos expectantes, a la espera, en silencio e incapaces de romperlo. Silencio entretejido de culpa y perversidad, en donde ella parece mirar ya solo hacia su propio interior, sus escasos movimientos no resultan visibles salvo por los monólogos disfrazados de diálogo y la intensificación y dureza con la cual son representados los gestos de quienes participan en el interrogatorio. La inminente amenaza entre sombras, velas que apenas iluminan la oscuridad que las circunstancias no atenúan, apenas son interrumpidas en el momento en que furtivamente coinciden las miradas, nadie

${ }^{1}$ Carl Dreyer, "La pasión de Juana de Arco", (1922), en https://vimeo.com/86583190 (acceso junio 30, 2020). 
esconde nada, nada hay para esconder, las miradas se entrecruzan solo para confirmar la justicia imposible del juicio que se lleva a cabo. En tanto, son los objetos allí presentes los que en silencio significan, comunican, hablan, esperando sin prisa su turno: la cruz, cuya sombra se deja ver en el suelo de la celda iluminada por la luz de la vela, los instrumentos de tortura, la ostia, la leña ardiendo y de cuyas brasas una luz caliente y mortecina nos convoca a formar parte del ejercicio de montaje al interior de la pantalla. Podríamos ser nosotros, la angustia existencial heideggeriana ante lo más auténtico que a cada uno le toca a travesar en vida por nuestra temporalidad en este por el mundo: la muerte, en este caso, la muerte de Juana. Uno-Todo, diría Heidegger, donde la totalidad se hace presente; la universalidad desde la que, según Rosenzweig, la filosofía se torna mentira piadosa, engaño, frente al fugaz y a la vez motivo perdurable y permanentemente repetido interés en olvidarnos de la muerte como el dominio más genuino de cuanto acontece a la vida humana.

La cruz, apenas una sombra significando la presencia divina silenciosa que se cierne como esperanza que no salva, pero aguarda, litúrgicamente la firma, conferida por dios mismo a la pluma y la tinta que corre por ella, no obstante, que Juana por dios y no por Francia peleaba. No es el hombre quien firma la sentencia que lleva a Juana a la muerte pasando por la tortura, es el silencio, la sombra, la presencia de dios que se revela y no del todo, una vez más el Uno-Todo heideggeriano. El film y en particular el interrogatorio -secuencia larga y medular del film- a Juana, resulta de una composición en la que el montaje, la iluminación, la perspectiva otorgada por los ángulos que dirige la cámara, el decorado y la presencia elegida de los objetos tanto en la celda como durante el juicio y la sentencia final, y los sonidos emitidos por el piano que ya acompaña más no como música de fondo, que ya acusa, hasta dictar la sentencia y la bajada del telón. Aquí, Wittgenstein, nos invitaría a plantearnos las preguntas con las cuales habríamos de abordar el drama visionado, porque de esto si se puede hablar... ¿̇o habría que callar?

\section{Lógica y mística. Aproximaciones a Ludwig Wittgenstein}


[...] Sucedió así: sentíde repente mi completa inanidad y comprendíque Dios podía exigir de mí lo que quisiera, con la consecuencia de que mi vida se convertiría inmediatamente en un sinsentido si no obedecía. Pensé inmediatamente si no podría explicar todo como una ilusión y no como una orden de Dios; pero me resultaba claro que entonces tendría que explicar cómo ilusión toda religión en mí. Que tendría que negar el sentido de la vida.

Tras alguna resistencia, seguí la orden, di la luz y me levanté. Allí estaba, de pie, en la habitación, con una sensación horrorosa. Fui hacia el espejo, me vi en él y mi imagen me miraba tan espantosamente que oculté mi rostro entre las manos. Sentí que estaba completamente destrozado y en las manos de Dios, que puede hacer conmigo lo que quiera a cada instante. Sentí que Dios puede obligarme en cualquier momento a tomar sobre mí lo más horrible, y que no estaba preparado para tomar sobre mí lo más horrible. Que no estoy preparado para renunciar ahora a la amistad y a toda dicha terrena. ¿Pero lo estaré alguna vez? [...] (Wittgenstein, 2006, s.n.).

Ludwig Wittgenstein emprende una crítica generalizada del lenguaje en su Tractatus, en gran parte motivada por el simbolismo lógico y el cálculo proposicional de Bertrand Russell y Gottlob Frege, intentando desde una revisión de la lógica de las matemáticas ofrecer una nueva lógica al lenguaje basada en las limitaciones inherentes y ordinarias de este mismo. Según Paul Engelmann

El positivismo sostiene-y esta es esencia-que aquello de lo que podemos hablar es to do lo que importa en la vida. En tanto que Wittgenstein cree ardientemente que todo aquello que realmente importa en la vida humana es precisamente aquello sobre lo que, desde su punto de vista, debemos guardar silencio. Cuando él asume empero inmensos trabajos para delimitar lo desprovisto de importancia [i.e., el alcance y límites del lenguaje ordinario] no está aplicando a hacer un reconocimiento de la línea costera de esa isla con una presión tan meticulosa, sino de lo que se está tratando es de los confines del océano (2009, p.241).

Para Wittgenstein, el significado del lenguaje no puede ser determinado basándose en la lógica proposicional ni en sus constantes lógicas, pues de la realidad no dice nada. Asimismo, considera 
que no existe una 'estructura objetiva de pensamiento' en la cual el sentido del lenguaje se origine, lo cual implica poner en consideración los límites relacionales del significado y la pluralidad de lenguajes como 'juego lingüístico', sin que ello implique la reducción de la multiplicidad de las proposiciones a una mera relación semántica (Wittgenstein, 1987). En una carta Wittgenstein expresa lo que él considera que había llevado a cabo en el Tractatus:

El punto central del libro es ético. En cierta ocasión quise incluir en el prefacio una frase que de hecho no se encuentra en él, pero que la transcribiré para usted aquí, porque acaso encuentre usted en ella una clave de la obra. Lo que quise escribir, pues, era esto: Mi trabajo consta de dos partes: la expuesta en él más todo lo que no he escrito. Y es esa segunda parte precisamente lo que es lo importante. Mi libro traza los límites de la esfera de lo ético de sde dentro, por así decirlo, y estoy convencido de que ésta es la UNICA manera rigurosa de trazar esos límites.

En breve, creo que allí donde muchos otros no están hoy en día haciendo más que asfixiar con gas, he acertado en mi libro a ponerlo todo en su sitio de una manera firme, guardando silencio sobre ellos. Y por esa razón, a menos que mucho me equivoque, el libro dirá una gran cantidad de cosas que usted mismo quiere decir. Lo único que ocurre es que usted no verá acaso lo que está dicho en el libro. Por el momento le recomendaría leer el prefacio y la conclusión, ya que contienen la expresión más directa del punto central del libro (Wittgenstein, 2000, p.35).

Para Wittgenstein, en el mundo de los hechos no hay nada que tenga que ver con los valores, por lo que "el sentido del mundo tiene que residir fuera de él. En el mundo todo es como es y todo sucede como sucede; en él no hay valor alguno, y si lo hubiera carecería de valor" (Wittgenstein, 2005, p.129). Y agrega, "está claro que la ética no resulta expresable. La ética es trascendental. (Ética y estética son una y la misma cosa)" (Wittgenstein, 2005, p.129). ${ }^{2}$ "El enigma no existe" (Wittgenstein, 2005, p.129). El Tractatus deviene en una suerte de misticismo del lenguaje en el

\footnotetext{
2 Ver, Ludwig Wittgenstein, Conferencia sobre ética. Con dos comentarios sobre la teoría del valor (Barcelona: Paidós, 1997).
} 
cual le concede al arte un rol significativo en la vida humana, siendo ésta la única capaz de expresar el verdadero significado de la vida. "No cómo sea el mundo es lo místico, sino que sea" (Wittgenstein, 2005, p.129). "El sentimiento del mundo como todo limitado es lo místico" (Wittgenstein, 2005, p.129). "Lo inexpresable, ciertamente, existe. Se muestra, es lo místico" (Wittgenstein, 2005, p.129). Wittgenstein llega básicamente a dos conclusiones en torno a la filosofía en esta obra:

El método correcto de la filosofía sería propiamente éste: no decir nada más que lo que se puede decir, o sea, proposiciones de la ciencia natural -o sea, algo que nada tiene que ver con la filosofía-, y entonces, cuantas veces alguien quisiera decir algo metafísico, probarle que en sus proposiciones no había dado significado a ciertos signos. Este método le resultaría insatisfactorio -no tendría el sentimiento de que le enseñábamos filosofía-, pero sería el único estrictamente correcto (Wittgenstein, 2005, p.129).

Y la otra conclusión, puesta además para cerrar la obra dice: "de lo que no se puede hablar hay que callar" (Wittgenstein, 2005, p.129). Afirmaba Karl Kraus sobre la posibilidad de llegar a comprender la mente de Wittgenstein: “¿Por qué escribe un hombre? Porque no posee carácter suficiente como para no escribir" (Kraus, 1998, p.254). Las matemáticas son para Wittgenstein una 'filosofía del juego', una escritura, es esa su lógica, una lógica que no depende de exterioridades, demostraciones o esencias. "El pensamiento está envuelto en una aureola" (Wittgenstein, 1967, p.62). Tanto las reglas de combinación como de relación de signos están todas dadas al interior del texto. "Queremos poner orden en nuestro conocimiento del uso del lenguaje: un orden con un objetivo determinado; uno de los muchos órdenes posibles; no el orden" (Wittgenstein, 2005, p.71). Dice Wittgenstein, "cuando decimos que toda palabra 'designa algo' no hemos dicho nada" (Wittgenstein, 1967, p.15). Lo cual nos conduce a cierta desesperación

Por el hecho de que no 'designe', no tenga 'significados' apriorísticamente determinables, se vierte en su ser-juego, en su convencionalidad, en las técnicas que lo expresan y lo aplican. No se trata ya de descubrir 'lo que está dentro', de obrar una aletheia, ni tampoco de engañarnos con una correspondencia entre 'esencia' de la proposición y 'estados de hecho', 
sino del análisis de nuestras múltiples formas de expresión, de la 'familia' de nuestros lenguajes (Cacciari, 1982, p.88).

Wittgenstein asume las limitaciones de la palabra para llegar a inspirar o lograr un contacto total con dios y los hombres. Se niega a recurrir al positivismo extremo que desea un engranaje perfecto entre palabras y hechos, donde obviamente no cabe misticismo alguno. Por ello para éste, la ética es el lugar sagrado del silencio, que no solo debemos identificar, sino respetar a manera de acto de fe, declarando implícitamente la existencia de un 'más allá' paralelo paradójicamente a lo expresado, pero que no puede ser explicado lógicamente. Es ahí donde podría operar el misticismo en su obra. Según la propia reflexión de Wittgenstein sobre el Tractatus, recogida por Janik y Toulmin, a saber, "[m]i trabajo consta de dos partes: la expuesta en él más todo lo que no he escrito. Y es esa segunda parte precisamente lo que es lo importante" (cursivas del autor), habría en él, entonces, "dos partes": la escrita y la no escrita, una expuesta y otra silenciada. La primera, además, diría lo que no importa, mientras que la segunda sería omitida, pero, al mismo tiempo, aludiría a lo que importa. El Tractatus estaría marcado, en este sentido, por una doble escisión; entre lo decible y lo indecible, y entre lo importante y lo no importante.

En lo referente al "deber de callar, imposibilidad de decir", lo indecible o importante parecen confluir simultáneamente, no obstante, de ser dos operaciones muy distintas. Por un lado, una interdicción (ino hables de lo que no puedes hablar! iSobre ello hay que callar!); por otro, una imposibilidad (iparece que hablas, pero en verdad no lo haces! ¡Callas incluso cuando dices!). Se trata de dos sentidos de 'poder': 1) 'poder/no poder' como estar (o no) 'permitido'; 2) 'poder/no poder' como 'capacidad' o 'incapacidad'. Son operaciones discernibles en la medida en que la interdicción sobre el decir presupone la posibilidad de hacerlo. No tendría sentido prohibir el hablar si éste no fuera, de alguna manera, posible. En otras palabras, de facto decimos lo que no se puede decir, hablamos de lo que no se puede hablar. Y precisamente sobre esta actitud recae la interdicción: el Tractatus conmina al silencio como un acallar o cesar el decir sobre lo importante. No obstante, según la segunda operación, aunque haya un decir, esto es, aunque se emitan, 
escuchen y lean palabras, este decir no dice nada. Parece que, en el ámbito de lo importante, podemos decir algo, pero lo cierto es que se trata de una apariencia de decir. No se trata ya de un decir posible que, sin embargo, debe ser evitado, sino de un decir que se muestra imposible. Por ello, una conclusión provisional sería: el silencio en el Tractatus aparece como deber de callar y, a la vez, imposibilidad de decir.

Sobre el 'decir aforístico, filosofía silente', el deber de callar, así como la insistencia en que es imposible hablar de lo importante, apuntan, de modo especial, a la filosofía que Heidegger y Rosenzweig, en los mismos años, acusaban de proporcionar sosiego o aquietamiento. El Tractatus es un enorme gesto filosófico que, en última instancia, se niega a sí mismo; solo acepta una justificación por su utilidad para desplegar la conminación al silencio. Eso es lo que significa la metáfora de la escalera que se abandona una vez empleada para subir. Porque el propio Tractatus, en efecto, dice algo que no se puede decir. Su estructura aforística, sin embargo, parece ser, a su manera, una forma de silencio.

En 6.5, Wittgenstein señala que en el ámbito de lo que puede ser dicho, caben las respuestas y, por tanto, las preguntas ('el enigma no existe'). A su vez, donde no hay respuesta, tampoco hay pregunta. Un problema que no puede recibir respuesta, como por ejemplo la vida, tampoco es susceptible de ser interrogado. Está más allá de lo que puede ser dicho; su 'solución', en verdad, es que desaparezca como problema. Queda abierta la cuestión de un preguntar que suspenda su tránsito a la respuesta, un preguntar demorado en sí mismo y en el límite. Como el que inició Heidegger.

Respecto al 'silencio lógico y místico', en la proposición 6.4 se habla de 'fuera' del mundo. La escisión mundo/fuera del mundo es equivalente a la escisión entre lo que importa y lo que no. La lógica, que constituye casi toda la 'parte' escrita del Tractatus, es el decir del mundo y, por este motivo, un decir sobre lo que no importa (no hay pedantería alguna en la afirmación de Wittgenstein según la cual el Tractatus resuelve todos los problemas de manera intocable y definitiva': es un texto que afirma la propia irrelevancia de tal resolución). El silencio lógico o silencio de la lógica es la irrelevancia del decir sobre el mundo. Ahora bien, ¿qué hay 'fuera' del 
mundo? El mero hay del mundo, sin un de dónde ni hacia dónde, sin verdad sobre por qué hay mundo y no nada. El bien (la voluntad) y la belleza. El enigma de la vida y la muerte. Dios. Es decir, todo lo que importa. Lo místico. El silencio místico o silencio de lo místico, con palabras o sin ellas, es un estar ante el mundo, pero sub specie aeterni, es decir, experimentándolo como limitación y anuncio permanente del 'afuera'. No solo el arte, también un acto ético como curar la herida del que sufre o entonar un rezo colectivamente podrían estar en la misma dirección. Todo ello queda recogido en la expresión 'lo místico'.

En lo que se refiere al 'decir mostrativo', según otra formulación de Wittgenstein, mientras si se puede utilizar la expresión- el decir dice, el no decir o silencio místico, muestra. 'Lo inexpresable' existe, pero solo se muestra. Por eso, escribe, quienes vieron el sentido de la vida o del mundo, experimentaron también la imposibilidad de decir, no pudieron decir en qué consistía tal sentido. O dijeron, pero solo mostrativamente, donde la experiencia de la culpa en el Juicio Final ofrece al culpable el sentido de la vida. Es un poema que muestra, no dice. La poesía, entendida de esta manera, es siempre un decir mostrativo o, lo que es igual, una forma de silencio.

Para Jacques Bouveresse, si interpretamos el Tractatus como una proposición ética -lo que no es más que un modo de hablar dado que no puede haber realmente 'proposiciones éticas'- el cierre de dicha obra ('Sobre lo que no se puede hablar, hay que callarse'), implica que "si el principio fundamental de la corrupción de los medios de expresión, ya sea en filosofía, en la moral o en el arte, lo constituye la pretensión de decir algo que cuando mucho puede ser mostrado, el remedio que hay que adoptar no puede ser más que una especie de ética del silencio obligado" (Bouveresse, 2006, p.153). Aquello que no puede ser dicho, corresponde al arte decirlo, en particular la poesía, la arquitectura y la música, pues debe estar contenido inexpresablemente en lo que expresa. Por ello, dice Kraus: "la arquitectura moderna es lo superfluo creado a partir del conocimiento correcto de una necesidad que se halla insatisfecha" (Kraus, 1955, p.15). Wittgenstein tanto en su filosofía como en idea de arquitectura (casa, su propia morada), se opone al ornamento, a lo que sobra, a lo que no es estrictamente funcional y austero, en resumen, hace tabula rasa como su contemporáneo en arquitectura, Adolf Loos. Wittgenstein llamaba tanto a Loos como a Kraus 'demoledores del 
adorno', mientras que Kraus llamaba a esta manifestación cultural al interior del imperio 'el laboratorio del fin del mundo’. "¿Qué puede aún querer expresar una época que tal vez, no tenga nada que expresar?"' (Bouveresse, 2006, p.162).

La filosofía del Tractatus se empata con el estilo arquitectónico de la casa. La arquitectura pues, es un gesto que debe expresar económicamente la forma más pura y abstracta posible. Tanto Wittgenstein, Kraus y Loos, desde sus trincheras protestan éticamente contra la hegemonía del ritualismo y el fariseísmo. Dice Gunter Gebauer:

[...] en una interpretación ética, el Tractatus y la casa se vuelven comparables entre sí: como intento de purificación del lenguaje de la corrupción moral y estética que contiene y como construcción de un sistema sintáctico y semántico puro, en el sentido ético. (Gebauer, 2009, p.229).

Y agrega sobre la casa que construyó y diseñó Wittgenstein: "La casa de la Kundmanngasse no necesita sostener un discurso sobre el mundo. Se orienta exclusivamente a la expresión de su estructura interna" (Gebauer, 2009, p.232). Así, las cosas que dicen algo lo dicen desde dentro y no hay que ir afuera de éstas para buscar lo que dicen, pues no se trata de algo personal o subjetivo, sino de una objetividad rigurosa.

Andoni Alonso, en su obra El arte de lo indecible. Wittgenstein y las vanguardias, nos dice que:

[...] el interés de Wittgenstein no reside en construir una teoría de la arquitectura con miras a una reforma social, sino en darse a sí mismo una respuesta concreta, ética, a un problema concreto gracias a una expresión vital y estética particular: su alcance se reduce a un ámbito puramente personal, como individuo que debe habitar esa casa (Alonso, 2002, p.86).

Considera que hay referentes comunes entre los motivos, las actitudes vitales y los pensamientos de Wittgenstein. Dice:

Los planteamientos son centrales dentro de este tema: la buscada soledad en el bosque, el deseo de una vida diferente en retiro, el agobio producido por la ciudad de Viena y la alta 
condición social, el deseo de un trabajo intelectual máximamente puro, y el amor por su hermana. A ello hay que añadir [...] la obligación continua de corregir lo ya hecho, característica que se aprecia en Wittgenstein no sólo en la casa vienesa, sino en los continuos titubeos respecto a su propia obra (Alonso, 2002, p.82).

De hecho, a Wittgenstein le parece antifilosófica toda reflexión sobre la realidad que no sea traducible a un lenguaje matemático puro:

Por ello la arquitectura de Wittgenstein, no puede consistir en ningún caso en crear ámbitos diferenciados, sino en presentar con la máxima pureza posible un espacio que haga patente en cada momento esa diferencia, que presente el aislamiento y la distinción completa entre los dos ámbitos" (Alonso, 2002, p.84).

La casa de la Kundmanngasse 'se muestra' de acuerdo con la proposición 6.4.2.1 del Tractatus, muestra la unión entre la ética y la estética, en donde orden y claridad se manifiestan. "Y justamente lo que falta es lo verdaderamente importante, la ausencia es lo que verdaderamente da valor el mundo" (Alonso, 2002, p.86). Wittgenstein quiere recuperar la sencillez vital y la paz que la ciudad le impide y que encuentra en su casa en el espacio rural; la casa actúa como un refugio frente a aquella y toda otra exterioridad superflua. La casa es un intento de mostración de aquel límite en el que cesa la lógica e inicia lo místico. Wittgenstein, filósofo-arquitecto, que, despojando a la construcción de ornamento, coloca a su habitante ante un mundo transparente y sin enigma. En tal despojo, se está ante el mundo, pero sub specie aeterni, es decir, ante el mundo como sordo anuncio de lo que está fuera de él. Dice el Tractatus: "El sentido del mundo tiene que residir fuera de él. En el mundo todo es como es y todo sucede como sucede; en él no hay valor alguno, y si lo hubiera carecería de valor" (6.41). La casa suspende el decir del cómo del mundo para mostrar que es. 


\section{Enmudecimiento y habla. Aproximaciones a Martin Heidegger}

A partir del ensayo "¿Qué es metafísica?" de Martin Heidegger, recogido en Hitos (1929) reflexionaremos sobre el silencio de Heidegger en estos años. Se trata de un texto con muchas correspondencias con las páginas finales del Tractatus. En general, intentaremos comprender cómo emerge el enmudecimiento en la experiencia de la angustia. Cuando Heidegger se pregunta ¿qué es metafísica?, se refiere no propiamente a la metafísica en general sino a cierta cuestión metafísica. Considera que la ciencia no quiere saber nada de la nada y en función de ello, no sabemos nada de ella, pero ¿qué pasa con la nada? ¿La admitimos o prescindimos de ella? "El preguntar por la nada (qué y cómo es) convierte a lo preguntado en su contrario. La pregunta se priva a sí misma de su propio objeto" (Heidegger, 2001, p.96), independientemente del rechazo de ésta por la ciencia. De hecho:

[...] la regla fundamental del pensar en general, a la que recurre corrientemente, esto es, el principio de no contradicción, lo 'lógico' universal, echa abajo esta pregunta. Efectivamente, el pensar, que esencialmente siempre es pensar de algo, dedicado a pensar la nada tendría que contravenir su propia esencia. (Heidegger, 2001, p.96).

¿Desde entonces preguntar por la nada?, ¿desde qué lógica? "Porque en efecto, la nada es la negación de la totalidad de lo ente, lo absolutamente no-ente" (Heidegger, 2001, p.96). Se pregunta Heidegger:

¿En dónde buscaremos la nada? ¿Cómo encontraremos la nada? ¿Acaso para encontrar algo no tenemos que saber ya, en general, que está ahí? [...] El hombre sólo es capaz de buscar cuando ya ha dado por supuesta la existencia de lo buscado, cuando presupone que está ahí presente. Pero ahora lo buscado es la nada [...] (Heidegger, 2001, p.97).

Paradójicamente hablamos de la nada como algo común y corriente cotidianamente.

La nada es la completa negación de la totalidad de lo ente. ¿Acaso esta característica de la nada no apunta ya en esa dirección desde la que precisamente es ella la única que puede salir a nuestro encuentro? Tiene que darse previamente la totalidad de lo ente a fin de que, 
simplemente como tal, dicha totalidad pueda caer bajo la negación, en la que después la nada misma debería mostrarse (Heidegger, 2001, p.96).

Para el Heidegger de finales de los años veinte, al igual que para el Wittgenstein del Tractatus, la lógica -decir sobre el mundo, decir sobre lo ente- no puede asumir el preguntar metafísico. En otras palabras, una pregunta como '¿qué es la nada?’ no puede ser, en modo alguno, respondida lógicamente. Cualquier respuesta bajo la forma "la nada es..." violenta, por definición, el principio lógico de no contradicción, pues hace de la nada, que no es, algo que es. La nada es no-ente y responder lo que ella es la hace ente. La salida de Wittgenstein fue mostrar los límites de la lógica y la escisión entre el mundo y el fuera del mundo, entre lo decible y lo indecible. Heidegger, en un andar afín, también aspira a quebrar el dominio de la lógica en la metafísica/filosofía e iniciar otro camino (metáfora esencial en su pensamiento). En “¿Qué es metafísica?”, texto dos años posterior a Ser y tiempo y aún en la línea de los textos juveniles, el camino tentado es el de hallar alguna experiencia en la que el preguntar metafísico referido a la totalidad de lo ente involucre al que pregunta -el Dasein- y, al mismo tiempo, arraigue en un ámbito irreductible a la lógica. Esta experiencia es la angustia. Rara, habitualmente adormecida y latente, la angustia refiere ta mbién a algo, es angustia ante algo, pero este algo no solo carece de determinación, sino que su determinación es esencialmente imposible. Aquí, y especialmente aquí, la nada se revela mediante una revelación simultáneamente existencial (el Dasein está involucrado en ella) y a-lógica. Lo ente se aparta, desaparece, se desvanece o huye, acosando, sobrecogiendo y aplastando en su partida al Dasein. Más aún, tal evanescencia de lo ente arrastra consigo al propio Dasein, quedando éste suspendido, despersonalizado (no es un 'yo'), impotente. El Dasein, angustiado y lejos de la vida cotidiana y del cuidado lógico-científico del mundo, no puede asirse a nada del mundo. Está ante una nada que se revela. Y entonces sobreviene el desplazamiento que introduce el silencio: "[I]a angustia nos deja sin palabra. Puesto que lo ente en su totalidad se escapa y precisamente ésa es la manera como nos acosa la nada, en su presencia enmudece toda pretensión de decir que algo es" (Heidegger, 2001, p.100). 
La charla insubstancial que busca acallar el silencio de la angustia o el decir sucinto que no logra explicar ante qué hubo angustia, muestran que aquí la nada se reveló. El efecto de esta revelación, comprendido a la vez como enmudecimiento (falta de palabras) y decir vacío (palabras que no dicen), constituye una de las versiones heideggerianas del silencio. No será, sin embargo, la única ni la última. Es posible que las técnicas de meditación oriental, inmóviles o en movimiento, constituyan experiencias de revelación de la nada ante el Dasein distintas a la angustia. Si este fuera el caso, serían también caminos existenciales y a-lógicos hacia el preguntar metafísico. Para Heidegger, son tres los peligros que acechan al pensar:

El peligro bueno, y por ende saludable, es la vecindad del poeta cantor. El peligro maligno, y por ende el más agudo, es el pensar mismo. Éste ha de pensar contra sí mismo, algo de lo que raras veces es capaz. El peligro debido a una mala constitución, y por ende desordenado, es el filosofar. (Heidegger, 2004, p.23).

Por ello considera Heidegger que el adviento del carácter poético del pensar está aún velado. Y dice (Heidegger, 2001, p.41):

\author{
Acampan los bosques \\ Precipítanse los arroyos \\ Perduran las rocas \\ Cae mansa la lluvia.
}

\begin{abstract}
Aguardan los campos
Brotan las fuentes

Moran los vientos

Medita la Gracia.
\end{abstract}

De esta manera, podemos considerar junto con Heidegger que es el anochecer y en soledad donde el mundo se hace libre, el momento en que "el viento se filtra en el silencio [y] el pensar, medroso, gusta de apaciguarse" (Heidegger, 2010, p.307). Por la noche "el mundo se hace libre" (Heidegger, 
2010, p.309) y "el lenguaje juega en el sonido del silencio" (Heidegger, 2010, p.309). De esta manera, la palabra silente es la llave y la cerradura a la vez de acceso a lo sencillo, un mundo en el que el lenguaje ha llegado al exceso y a la vacuidad, a la inexpresabilidad y a la negación del pensamiento. "Lo difícil de guardar silencio es hablar [...] guardar silencio exige realizar el discurso, pues, sin esta realización, guardar silencio se degradaría a mero enmudecer" (Heidegger, 2010, p.313). La soledad es la posibilidad real de unirse a uno mismo, de alcanzar la verdadera libertad en el mundo. El camino habla, es decir, consiste en un habla que ciertamente es silencioso, y, no obstante, dice. Y, en este sentido, el silencio como 'mero enmudecer' predominante en los años veinte, ha sido abandonado. Silencio y decir no se oponen. En segundo lugar, cuando se compara el habla del camino con un aliento, se está transmitiendo la idea de su fragilidad. Por un lado, el habla del camino es frágil en la medida en que solo dice si encuentra a alguien que escuche su decir, un Dasein, el pensador del enigma, el campesino en la siega, por ejemplo, en cualquier caso, siempre 'los pocos', aquellos que logran permaneciendo serenos, no desviarse o desencaminarse en el cálculo técnico.

Por otro lado, es un habla frágil en el sentido de que es tácito, con omisiones y secretos, reveses infinitos, siempre cargado de elementos no dichos que se sustraen en el mismo momento en el que dice. Parafraseando el propio pasaje de Heidegger: al igual que Dios, el habla del camino solo es tal en lo que su decir no dice. Por último, lo que dice el habla del camino, su aliento, es lo sencillo; un silencio expandido que llega incluso a aquellos que murieron; o, si se prefiere, una renuncia que, lejos de quitar, dona. Y aquí emerge la cuestión del origen/comienzo/inicio, camino que habría que recorrer, si se quisiera seguir lo que fue el pensamiento de Heidegger desde los años cuarenta hasta el final de su vida. ¿Es el alma que habla? ¿Es el mundo que habla? ¿Es Dios que habla? Alma, mundo y Dios son los tres grandes 'objetos' de la metafísica occidental. La respuesta ¿se puede llamar así?- de Heidegger es: habla el camino de campo.

El camino de campo es una 'imagen' del Ser. Sobre lo que llamé 'habla poético-pensante', cabe señalar, siguiendo reflexiones del propio Heidegger recogidas en el volumen Pensamientos poéticos, que no se trata de poemas ni de filosofía ritmada y en verso. Es un habla que no vela 
doctrina o teoría alguna. A diferencia del decir poético, no recurre a imágenes; éstas solo aparecen en él cuando el despliegue de un decir sin imágenes, que sería en principio su tarea, no logra alcanzar lo que busca. ¿De qué se trata, entonces, en este decir? Heidegger recuerda, como indicación, el (llamado) 'poema' de Parménides. Pero advierte, inmediatamente, que no se trata de un lenguaje que retorna -sea lo que sea que eso signifique- a la Grecia perdida, sino de uno que se hace cargo del destino/la llamada del ser que nos corresponde en este momento. También dice que es un habla que aspira a cuidar el silencio originario-como aquel silencio del camino de campo.

\section{Gramática y liturgia. Aproximaciones a Franz Rosenzweig}

Para Rosenzwieg, "el nuevo pensamiento" se trata de un nuevo sistema de filosofía. Anteriormente y hasta ese momento, toda filosofía se ha ocupado sólo de preguntar por la esencia. ¿Qué significa esto? La filosofía cuando pregunta por la esencia no hace más que dar vueltas sobre aquello mismo que pregunta:

[...] el mundo no puede por cierto ser mundo, Dios ser Dios, la persona ser persona: todo debe ser propiamente otra cosa. Si fueran realmente sólo lo que son y no otra cosa, la filosofía resultaría, por último- ¡Dios nos libre y guarde! - superflua. (Rosenzweig, 2007, p.319).

Todas las filosofías anteriores se preocupan por preguntar por lo que hoy identificamos como lo que ha sido incansablemente reducido al 'yo':

Esta reducción o fundamentación del mundo y la experiencia de Dios al 'yo que experimenta', hoy se da tan sobreentendida para el pensamiento científico que quien no crea en ese dogma y prefiera reducir sus experiencias del mundo al mundo y sus experiencias de Dios a Dios, sencillamente no es tomado en serio. (Rosenzweig, 2007, p.320).

Considera Rosenzweig que de esta manera la filosofía del pensamiento queda enfrentada históricamente a la filosofía de la experiencia, pues nos hemos acostumbrado a preguntarnos por Dios y por el mundo desde el 'es' como si éstos ya estuviesen dados. Ni el mundo es sólo lo 
mundano, ni Dios es sólo divino. Si así fuese, entonces ¿para qué la filosofía? Mundo, Hombre, Dios en términos de 'esencia' no hay jerarquías ontológicas, por ello, para preguntas por la esencia no se encontrarán más que respuestas tautológicas, por ejemplo: “Dios es sólo divino, el ser humano es sólo humano, el mundo es sólo mundano; se puede cavar en ellos tan hondo como se quiera: se hallará una y otra vez sólo a ellos mismos" (Rosenzweig, 2007, p.321). La esencia de ninguno de estos tres conceptos o ideas es más o menos accesible al ser humano, de hecho, estos conceptos se metamorfosean, por lo que al pensarlos pudiese resultar que son algo distinto a lo que se supone que son. Escribe Goethe en el Diván oriental-occidental

Es estúpido que todo el mundo esté alabando su opinión particular.

Si el Islam significa sumisión a Dios, todos vivimos y morimos como musulmanes. ${ }^{3}$

Divino, humano, mundano... ¿qué son? ¿En qué o dónde podría radicar su esencialidad, considerando que constituyen el presupuesto de nuestra realidad? ¿En verdad debe estar presente el 'yo' de los últimos tres siglos? ¿Si la respuesta es afirmativa, cómo podríamos estar ciertos del conocimiento que poseemos? ¿Sobre qué ejercemos la narración, sobre qué acontecimientos? ¿Qué y cómo comprender en el momento oportuno? Continúa Goethe

¿Por qué la verdad es lejana y remota,

y se refugia en el hondo abismo?

¡Nadie comprende en el momento oportuno!

Si se comprendiera en el momento oportuno,

la verdad sería cercana y amplia,

y sería adorable y benigna.

3 Ver, Wolfgang Goethe, "Libro de las sentencias", en West-östlicher Divan (Stuttgart: Cottaische Buchhandlung, 1989). 
Rosenzweig propone una filosofía basada en la experiencia, que en lugar del método del pensar se base en el método del hablar, pues hablar se encuentra atado al tiempo y vive la vida de los otros, mientras que el método del pensar siempre es solitario. "Necesitar tiempo significa: no poder anticipar nada, tener que esperar todo, ser dependiente del otro con lo más propio de uno mismo [...] Hablar significa hablar para alguien y pensar para alguien" (Rosenzweig, 2007, p.329). La oración como acción y no "mera" pasividad pasiva. La libertad de la acción del amor como voluntad de Dios. Ambas ideas siempre en conclave entre el solitario y el silencio: "La oración funda el orden humano del mundo" (Rosenzweig, 2006, p.322). Y, aun así, además de la magia que conlleva la oración, se corre cierto riesgo en ésta. La luz proyectada en el tiempo y en el espacio, orientada del presente hacia el futuro, hacia los tiempos que vendrán a través de la liturgia y el silencio que adivinan lo verdaderamente eterno (la ruta de la estrella). "Lo eterno se oculta detrás. Son la luz en las que vemos la luz: silenciosa anticipación de un mundo que luce en el silencio del futuro" (Rosenzweig, 2006, p.351). La ruta de la estrella es la ruta del silencio, se construye con éste. "Se trata de un silencio que no es que carezca todavía de palabras, como la mudez del antemundo, sino que ya no precisa de la palabra. Es el silencio de la comprensión perfecta" (Rosenzweig, 2006, p.352). Tal vez por ello afirmaba lehuda Halevi

Pero la meta principal es otra: hacer que el lector tome cada poema como una cosa en sí, de la misma manera en que el poeta lo ha compuesto como una cosa en sí y de la misma manera en que lo cantaba y escuchaba el cantor y el oyente en el lugar para el que está destinado, como lo canta y escucha, lo cantará y escuchará. Es decir, que el lector pase de ser lector y crítico a ser huésped y amigo del poema (Rosenzweig, 2007, p.311).

¿Sabíamos algo del límite? En el Tractatus, Wittgenstein decía: lo que está más allá del límite, eso es lo místico. El pasaje de La estrella de la redención se sitúa en ese mismo lugar: "La oración es la fuerza que traslada más allá del umbral” (Rosenzweig, 2006, p.351). 'Umbral', sin embargo, parece añadir algo a 'límite': significa, ciertamente, el borde, pero también su oscuridad o su sombra. Los umbrales -podríamos decir- son límites umbríos. La oración-rezo, plegaria-cruza el umbral. Más 
allá de las diferenciaciones que Rosenzweig introduce entre sus tipos, la oración que remite al silencio es aquella que consiste en ser súplica por la venida del Reino. Si se insiste en la imagen del umbral, hay que decir que la oración clama, en el límite, por la iluminación, por el advenimiento de la luz. 'Luz' remite a 'Reino', y ‘Reino' es aquí al menos dos cosas: eternidad y redención. La oración cultual y, en general, el culto, constituyen imágenes terrenales -imágenes no figurativas, reales- de la eternidad. Son modos de acoger, cobijar, posibilitar la morada/habitación o hacer sitio al huésped.

En este sentido, orar culturalmente es un modo de hospitalidad; una hospitalidad que se despliega, además, en común, de manera asamblearia, comunitaria. En el culto, un huésped eterno es acogido en una casa temporal. Esa es la súplica de la comunidad orante: que la eternidad se haga tiempo, que lo que no pasa habite en el instante que pasa, que la semilla de la redención se introduzca en la historia no-redimida. Visibilizar lo invisible; hacer de lo más lejano, lo más próximo. Esta hospitalidad con el otro es exactamente la idea de la traducción de Rosenzweig: no 'germanizar lo extranjero' sino 'extranjerizar lo germánico'. Tras la traducción, “la lengua [de acogida] tendrá escribe para la edición de los poemas de Halevi-, luego de que ha hablado, un rostro distinto del anterior" (Rosenzweig, 2006, p.351). El traductor, como el hablante y el pensador, hace que una lengua acoja en sí a otra, renovándose radicalmente: "Si la voz extranjera tiene algo para decir, la lengua [que la acoge] debe verse luego distinta de cómo era antes" (Rosenzweig, 2006, p.294). La oración cultual se orienta a la iluminación del final, del instante eterno -nótese el oxímoron- en el que todo se acaba y cumple. En este sentido habilita el conocimiento de algo, pero tal algo no es contemporáneo de o simultáneo con la oración que permite conocerlo.

¿Qué significa esta no-contemporaneidad entre la súplica y lo que ella hace conocer? La oración en común, indisociable de la gestualidad litúrgica, es lo que da lugar en el hoy a lo eterno. Pero lo eterno, el Reino, es futuro, no algo ya dado. Es algo por venir, no algo ya venido. Por eso, la oración en común y la liturgia, escribe Rosenzweig, 'representan' el futuro. Para pensar la relación entre súplica/liturgia y Reino, instante y eternidad, presente y futuro, quizá un término más preciso que 'representación' sea 'alegoría', en el sentido que le dio Walter Benjamin: en la liturgia no 
conocemos la luz en sí misma, sino una alegoría a partir de la cual conocemos la luz que, en cuanto (aún) no dada, permanece no-conocida. En otras palabras, no conocemos la luz en sí misma sino solo a través de la luz de su alegoría. Es precisamente en esta relación entre la alegoría y lo alegorizado por ella donde aparece el silencio.

Ambos aspectos, la alegoría y lo alegorizado, resguardan el silencio, se manifiestan silenciosamente. Es silente la súplica como silente es el Reino; es silente la liturgia presente como silente es la eternidad futura. Se trata del silencio de un doble gesto. Rosenzweig recuerda que, habitualmente, el gesto aparece cuando las palabras fallan. Por ejemplo, cuando dos hablantes carecen de una lengua común y, para comunicarse, recurren al balbuceo gestual como método para procurarse lo que las palabras no les pueden dar. El gesto es, entonces, un suplemento del lenguaje verbal. En la liturgia, sin embargo, no es la palabra sino el gesto -de nuevo: común, comunitario- lo supremo. "La liturgia redime al gesto de los grilletes que lo tienen sometido a ser el criado torpe del lenguaje, y lo convierte en algo que es más que el lenguaje" (Rosenzweig, 2006, p.352).

Pero hay otro gesto silente que no es el de la comunidad creyente en la liturgia. La luz a la que se suplica clama, para que venga, no habla, solo luce. Ella no se abandona, exterioriza o aliena/enajena, como el lenguaje habitual. Permanece en sí misma. Irradia como un 'rostro', como la elocuencia de un 'ojo' que de pronto aparece. Un rostro-ojo que dice, aunque de otra manera. Gestualmente. No carece de palabras, no precisa de ellas. Es el gesto de lo eterno. A propósito del film de Dreyer: el 'silencio de Dios'. Eso es lo que, a su modo, parece expresar el poema religioso de Halevi, esa poesía que necesita del calendario litúrgico para ser acogida, en la recitación del entonador y el canto de la comunidad. Para Halevi, hay un camino a lo eterno, uno que hace hoy a lo eterno, o nos hace habitar las 'moradas' divinas. Pero este camino no es, por cierto, el de las 'palabras oscuras'.

No fueron palabras oscuras las que me acercaron a ti

Es el camino de una iluminación.

Te he visto, Señor

A partir del silencio de la liturgia: 
Vi las bellas oblaciones divinas,

holocaustos, sacrificios y libaciones,

y nubes de humo girando, densas.

Con agrado escuché el canto de levitas

al juntarse para disponer la liturgia.

Ese es el camino. Allí, cuando la liturgia termina -el tiempo pasa-, lo eterno, no obstante, permanece: deja en el tiempo una huella que, en el recuerdo y la espera de los que suplican comunitariamente, no pasa.

$$
\begin{aligned}
& \text { Todo se terminó, pero al despertar } \\
& \text { aún estabas conmigo, Señor. }
\end{aligned}
$$

Rosenzweig comenta:

[...] la oración, cuando ilumina, les muestra a los ojos la meta más lejana. Pero como el orante está en el punto preciso de su personalidad, esta meta lejanísima y común a todos se les aparece en un primer plano de perspectiva completamente personal: la perspectiva, precisamente, del punto donde él está" (Rosenzweig, 2006, p.325).

En la ópera Moses und Aron, ${ }^{4}$ de Arnold Schönberg, hacia el final del Acto II, cuando el dramatismo de la obra alcanza la cima, Moisés dice:

!Oh, palabra, tú, palabra, que me faltas!

E inmediatamente cae al suelo.

\footnotetext{
4 Ver, Arnold Schönberg, "Moses und Aaron", http://www.kareol.es/obras/moisesyaaron/acto1.htm (acceso agosto 9, 2016).
} 


\section{Conclusiones}

Rosenzweig pone en juego algo que está también presente de manera relevante en Wittgenstein y Heidegger: la experiencia. Me parece que para todos ellos la experiencia vital es precisamente la angustia ante la muerte, además de la facticidad planteada por Rosenzweig y Wittgenstein. En el último trabajo de Rosenzweig acerca de La estrella de la redención, podemos identificar una cierta mofa de la filosofía en tanto acercamiento a los hechos, desde un entramado conceptual ideal que se refiere más a sí mismo como sistema de pensamiento, a su lógica interna, que ocuparse por establecer efectivamente un puente entre la experiencia, la reflexión y las sensaciones que preceden al habla del pensante en su interacción con lo mundano. Hay una 'desconfianza' en los tres filósofos, en cuanto a que las palabras puedan acceder al plano de lo verdadero sin caer en tautologías, en secuencias conceptuales 'cerradas' que se 'muerden la cola' y terminan para el lego, en ser redundantes... y por lo menos dos de ellos encuentran en él o los lenguajes poéticos la mayor posibilidad de acercamiento ante lo indecible, en uno trágicamente asumido, en los otros, como aparejado 'naturalmente' en la vida humana, aunque obviamente dotado de un papel que manifiesta en ese silencio su indeterminación, su imposibilidad de ser explicado.

En Heidegger, la experiencia del camino, su configuración estética, la experiencia concreta del andar y las señales naturales y artificiales del camino, son un punto de inflexión para ir perfilando su idea del silencio, como aparejado fraternalmente a la experiencia, mucho más que el discurso. Para entregarnos de manera directa su propio asumir este silencio, dejando sólo caer unas líneas, unos versos cortos, que tienen esa levedad que muestra a un compañero fiel y silencioso a su lado. Para Wittgenstein, la experiencia de la vida, sabiendo nuestra condición de mortales, es en esencia 'dramática', es una lucha por entender a Dios en su silencio y tratar de entenderse con éste a través de una postura física, desde la oración, desde la insignificancia individual en esa noche narrada. En resumen, no hay palabras que puedan 'traducir' la experiencia sin reducirla y en todo caso, Wittgenstein estaría más del lado del lenguaje ordinario para la descripción, que desde la construcción teórica que anula 'esas' experiencias humanas trascendentales, convirtiéndola en un 'juego del lenguaje', en una confusión de sentidos. 
Desde mi punto de vista, se podría, en primer lugar, comparar lo insubstancial del habla lógica en Rosenzweig con lo que llamamos 'silencio lógico' en Wittgenstein, el cual aparecía como un decir que se hacía irrelevante al estar dirigido a lo que no importa. Pero, en segundo lugar, y quizá de un modo más hondo, en Rosenzweig se puede detectar un silencio distinto, un silencio gramatical o silencio incrustado en el habla gramatical. ¿En qué consiste? ¿Dónde situarlo? Se puede encontrar en la simultánea intensificación del tiempo y el otro que radica en el estar a la espera. Aquí, de nuevo, el silencio no es lo contrario del decir. Es solo ese instante en el que, como ocurre habitualmente en la conversación, yo ya he dicho algo, pero el otro aún no ha dicho nada. Es aquella espera que sigue a mí decir, una espera que se orienta al decir del otro. Estando a la espera, no puedo anticipar si esas otras palabras, que no son las mías, serán dichas o no, si vendrán o no... en última instancia, no puedo anticipar si mi espera será infinita. Tampoco puedo anticipar, en el caso de que vengan, si la espera será larga o corta, cuáles serán esas palabras, si continuarán las mías o las interrumpirán, si afirmarán o negarán... Simplemente permanezco, en recogimiento silencioso, a la espera de la palabra del otro, de la palabra que (quizá) viene. El silencio gramatical de Rosenzweig es este silencio de la espera.

\section{Referencias}

Alonso, A. (2002), El arte de lo indecible. Wittgenstein y las vanguardias, Cáceres: Universidad de Extremadura.

Bouveresse, J. (2006), Wittgenstein: la modernidad, el progreso y la decadencia, México: UNAMInstituto de Investigaciones Filosóficas.

Cacciari, M. (1982), Krisis. Ensayo sobre la crisis del pensamiento negativo de Nietzsche a Wittgenstein, México: SigloXXI Editores.

Engelmann, P. (2009), "Recuerdos de Ludwig Wittgenstein", en Wittgenstein, Ludwig y Paul Engelmann, Cartas, encuentros, recuerdos, Valencia: Pre-textos.

Gebauer, G. (2009), Die Syntax des Schweigens, München: C.H.Beck. 
Goethe, W. (1989), "Libro de las sentencias", en West-östlicher Divan, Stuttgart: Cottaische Buchhandlung.

Heidegger, M. (2010), Pensamientos poéticos, Barcelona: Herder.

Heidegger, M. (2004), Desde la experiencia del pensar, Madrid: Ábada Editores.

Heidegger, M. (2001), Hitos, Madrid: Alianza Editorial.

Janik, A. y Toulmin, S. (1998), La Viena de Wittgenstein, Madrid: Taurus.

Kraus, K. (1955), Beim Wort genommen, München: Kosel Verlag.

Rosenzweig, F. (2007), "El nuevo pensamiento", en Lo humano, lo divino y lo mundano, Buenos Aires, Ediciones Lilmod: Libros de la Araucaria.

Rosenzweig, F. (2006), La estrella de la redención, Salamanca: Ediciones Sígueme.

Wittgenstein, L. (2007), Observaciones filosóficas, México: Instituto de Investigaciones Filosóficas/UNAM.

Wittgenstein, L. (2006), Luz y sombra: una vivencia (-sueño) nocturna y un fragmento epistolar, Valencia: Pre-Textos.

Wittgenstein, L. (2005), Tractatus logico-philosophicus, Madrid: Alianza Editorial.

Wittgenstein, L. (2000), Briefe an Ludwig von Ficker, Innsbruck: Brenner Studien, vol. I.

Wittgenstein, L. (1997), Conferencia sobre ética. Con dos comentarios sobre la teoría del valor, Barcelona: Paidós.

Wittgenstein, L. (1967), Ricerche filosofische, Paris: Gallimard. 